Review

\title{
Reproductive control by others: means, perpetrators and effects
}

Sam Rowlands ${ }^{1}$

Susan Walker ${ }^{2}$

${ }^{1}$ Faculty of Health and Social Sciences

Bournemouth University

srowlands@bournemouth.ac.uk

${ }^{2}$ Faculty of Health, Social Care and Education

Anglia Ruskin University, Chelmsford \& Cambridge

susan.walker@anglia.ac.uk

Keywords: abortion, coercion, contraceptive sabotage, control, ethics, reproductive rights, pregnancy, reproductive autonomy

Word count: Abstract 236 words; Main text 2,975 words

Correspondence to:

Sam Rowlands, Centre of Postgraduate Medical Research \& Education, Bournemouth University, Royal London House, Christchurch Road, Bournemouth, BH1 3LT, UK Tel: +4401202962782 


\section{ABSTRACT}

\section{Background}

Reproductive control of women by others comprises a wide range of behaviours, from persuasion, to pressure such as emotional blackmail, societal or family expectations through to threats of or actual physical violence. It is defined as behaviours that interfere with women's reproductive autonomy as well as any actions that pressurise or coerce a woman into initiating or terminating a pregnancy

Method

Narrative review based on a search of medical and social science literature.

Results

Reproductive control by others includes control or coercion over decisions about becoming pregnant and also about continuing or terminating a pregnancy. It can be carried out by intimate partners, the wider family, or as part of criminal behaviour. One form is contraceptive sabotage, which invalidates the consent given to sex. Contraceptive sabotage includes the newly-described behaviour of 'stealthing': the covert removal of a condom during sex. Reproductive control by others is separate from intimate partner violence but there are similarities and the phenomena overlap. Reproductive control by others is reported by as many as one quarter of women attending sexual and reproductive healthcare services. Those treating such women should be familiar with the concept and how to ameliorate its affects. Screening questions for its detection have been developed as well as interventions to reduce its risk.

Conclusions

Reproductive control by others is common and those working in women's health should be familiar with the concept and with screening tools used to detect it.

\section{Key message points}

- Control over women's reproductive autonomy by others is common and healthcare professionals need to ask specific questions about it

- Control or coercion over decision-making about use of contraception or about an established pregnancy comes in a wide range of forms

- Contraceptive sabotage is deliberate interference with agreed use of contraception, so invalidating consent to sex 


\section{BACKGROUND}

Women should be able to choose freely whether and when they wish to have a family. In other words, they should have reproductive autonomy; by definition, reproductive autonomy means being free from coercion and violence. ${ }^{1}$ Various barriers to this exist ${ }^{2}$, which are the topic of this review.

Whilst intimate partner violence and reproductive coercion can occur between same sex couples and can be perpetrated by women upon men $^{3}$, the focus of this review is reproductive coercion in which women are the coerced party. Reproductive control by others $(\mathrm{RC})$ is common and many women presenting to contraception and sexual health services may be currently subject to it, may have experienced it in the past or may be at risk of experiencing it. RC may be a factor in contraceptive 'failure' or non-adherence; frequent requests for emergency contraception; for pregnancy or sexually transmitted infection (STI) testing; or in having more than one abortion. This review is aimed at readers without specific knowledge of intimate partner violence and seeks to clarify the forms which RC can take, summarises relevant epidemiology, examines types of perpetrator and finishes with suggestions for screening for, and identifying, women experiencing it.

Reproductive coercion was first described in a systematic review in $2010^{4}$. More recent reviews cover literature up to the year 2015 in the USA ${ }^{5}$ and in other countries ${ }^{6}$. Our review goes wider than previous reviews in its remit, to include family pressure and criminal activity, and extends the time period to 2017.

\section{METHODOLOGY}

MEDLINE, CINAHL, PsycINFO, SocINDEX, Academic Search and British Library searches were conducted for the terms 'reproductive coercion', 'reproductive control' and 'contraceptive sabotage' since 2010, when the concept was first reported in mainstream sexual and reproductive health literature. Search parameters are shown in Table 1. This narrative review describes a range of behaviours but does not attempt to analyse underlying motivations.

\section{WHAT IS REPRODUCTIVE CONTROL?}

\section{Definition}

Reproductive control over women, in the context of this review, is external and exerted by others. It is not to be confused with methods of fertility control (or birth control) which allow women themselves to be in control of their own reproductive lives. 
Reproductive control of women by others comprises a wide range of behaviours, from persuasion to pressure such as emotional blackmail, societal or family expectations through to threats of or actual physical violence. It can be defined as actions that interfere with a woman's reproductive intentions and any actions that pressurise or coerce a woman into initiating or terminating a pregnancy ${ }^{57}$. In this review the authors define RC more widely than many others, in the context of gendered control, coercion and violence ${ }^{8}$. RC fundamentally interferes with women's reproductive autonomy generally ${ }^{9}$ and with their autonomous sexual decision-making more specifically ${ }^{10}$. Reproductive coercion is a subset of reproductive control and occurs when a credible threat of harm or force is made to control a woman ${ }^{511}$. The perpetrators of reproductive control and reproductive coercion may be sexual partners, but can extend beyond the intimate partner relationship, as outlined below.

Reproductive control is mediated through the decisions around whether or not to start, continue or terminate a pregnancy, including deployment of contraception, and may be exercised at various times in relation to intercourse, conception, gestation and delivery. It may occur before or during sex, with a refusal to use contraception, during the period of attempting to conceive or at any time in the gestation of an established pregnancy ${ }^{12}$. Reproductive control is associated with negative mental health outcomes ${ }^{13}$.

\section{Perpetrators of reproductive control}

In addition to intimate partners, the sources of RC include wider family members, acting alone or together. Cultural and social norms in a society can reinforce RC and may link individual and family behaviour.

\section{EPIDEMIOLOGY}

As many as one-quarter of women of reproductive age attending for sexual and reproductive health services give a history of ever having suffered RC (see Table 2). A negative association has been found between RC and contraceptive and sexual self-efficacy (planning for and assumption of responsibility for the direction of sexual activity and responsibility for contraceptive use $)^{10}$.

It has been known for some time that unintended pregnancy occurs more frequently in abusive relationships ${ }^{14}$. Miller et al found that the risk of unintended pregnancy doubled in those who suffered both intimate partner violence (IPV) and reproductive coercion ${ }^{15}$. Several studies have shown a positive association between RC and unintended pregnancy ${ }^{10}$ 1617. A positive association has also been found between IPV and having an abortion; the association is even more pronounced when the women undergoing an abortion report that 
their partner has no knowledge of the abortion ${ }^{18}$. There is a strong positive association between RC and IPV ${ }^{15}$ 19-21. Women experiencing IPV are twice as likely to have a male partner who refuses to use contraception and to report unintended pregnancy and up to three times more likely to give birth as an adolescent, compared to those not experiencing such violence ${ }^{9}$.

Past experiences of RC decrease the odds of contraceptive use at last vaginal sex ${ }^{10}$. Women who have recently experienced RC are more likely to request pregnancy testing and STI testing and to seek emergency contraception ${ }^{17}$. Among US women in a reproductive healthcare setting, Black and multiracial ethnicity are both positively associated with $\mathrm{RC}^{22-24}$. Younger women are more frequent victims of $\mathrm{RC}^{1625}$. Reproductive control is more likely to occur in longer-term relationships than with casual partners ${ }^{10}$.

\section{FORMS OF REPRODUCTIVE CONTROL PERPETRATED BY INTIMATE PARTNERS}

\section{Unprotected sex}

One of the commonest RC behaviours is for male partners to tell women not to use contraception ${ }^{26}$. Partners themselves may also refuse to use condoms or tell a woman later that they did not use a condom ${ }^{27}$. In addition to this, some women may be prevented from obtaining initial or repeat supplies of contraception ${ }^{25}$. Women report that their partners want to have children, particularly male children, or may want to maintain a permanent connection with their female partner" 25 . Emotional blackmail may be used i.e. "You would have my baby if you loved $\mathrm{me}^{\prime \prime}$. More serious threats of actual violence, deprivation of food, threats of removal of children or actual forced intercourse may also be used ${ }^{25} 26$. Partner infidelity is a common associated behaviour ${ }^{25}$.

\section{Contraceptive sabotage}

As with the topic of RC in general, contraceptive sabotage can be perpetrated by various means: from a reluctance or poor effort to use condoms ${ }^{28}$, through to a violent and invasive removal of an intrauterine contraceptive device. It includes 'stealthing', first publicised by Alexandra Brodsky in April 201729. This is defined as the non-consensual, surreptitious removal of a condom during sex, when consent has been given only for condom-protected sex. Alternatively, a male partner may falsely state that he has had a vasectomy. The commonest means of contraceptive sabotage are failure to practise withdrawal, as previously agreed, or non-use of condoms. Contraceptive sabotage also includes various actions including piercing condoms or other barrier methods, throwing away supplies of oral contraceptives or forcibly removing transdermal patches, vaginal rings or intrauterine devices ${ }^{5}$. 
Contraceptive sabotage interacts and overlaps with sexual coercion and violence. In such cases, consent to sex has been given on the understanding that contraception will be used. Contraceptive sabotage thus invalidates consent, but there are complicated arguments as to how any legal redress would be sought against saboteurs ${ }^{29-31}$. Currently, in most jurisdictions, it seems likely that cases of contraceptive sabotage taken to court would be unsuccessful. However, in Canada, a man did receive an 18-month prison sentence for depriving his partner of her ability to consent to $\operatorname{sex}^{32}$.

\section{Women's actions to reassert reproductive autonomy}

Women's reactions to RC include capitulation, seeking contraceptive methods that can be used covertly or ending the relationship. In some studies women report attempting to avoid pregnancy by concealing their use of contraception. Contraceptives with varying degrees of concealability are injections, implants, intrauterine devices and sterilisation. Injectables are 'invisible' as there are no tell-tale signs (palpable rod, threads at the cervix or abdominal scars). But even when concealable contraceptives are being deployed, a partner may discover an appointment on a card, in an email or on a smartphone. Some women being subjected to IPV will be put off using concealable methods because of the fear of retaliation if their partner were to find out. Experience of RC is associated with fear of asking a partner to use a condom and fear of the consequences of refusing to have sex with a partner ${ }^{22}$. Women in violent relationships risk an escalation of violence if they try to negotiate contraceptive use $\mathrm{e}^{25}$.

Pregnancy testing may also need to be concealed. Flushable pregnancy tests have become available, the advantage of which (in addition to their ecological credentials) is that no 'evidence' of having used them remains discoverable ${ }^{33}$.

\section{Coerced continuation of a pregnancy}

Reproductive control can include the insistence on continuation of a pregnancy which the women regards as unintended or unwanted ${ }^{6}$. It is carried out by a variety of means ranging from physical violence, threats of violence or forced sex, to subtler acts such as threats to withhold resources or to have a baby with someone else, if the pregnancy is terminated. Some partners refuse to provide childcare or transport on the day of an appointment with an abortion provider or sabotage a woman's fasting regimen prior to her procedure under general anaesthetic ${ }^{5}$.

Medical abortion may suit a woman being subjected to reproductive control better than surgical abortion ${ }^{34}$. There is no post-anaesthetic recovery necessary and women can 
attribute the bleeding to a spontaneous miscarriage. Jurisdictions that allow misoprostol to be taken at home greatly facilitate this process.

\section{Forced or induced termination of an established pregnancy}

Induced (therapeutic) abortion may be coerced ${ }^{35}$ or a woman may be assaulted with the intention of causing a miscarriage. It has been shown that exposure to gender-based violence predicts having an abortion ${ }^{3637}$. A survey of lower-income US men demonstrated that those who admitted that they had perpetrated IPV were more likely than those who had not to have been involved with a pregnancy that ended in abortion ${ }^{38}$. The abusive men were also more likely to have been in conflict with their partner at the time over the pregnancy, either in seeking to force an abortion or to prevent an abortion.

At the extreme end of the spectrum, male partners have covertly spiked either food or drink with abortifacients. This criminal activity has been reported from Norway ${ }^{39}$, the $\mathrm{UK}^{40}$ and the USA ${ }^{41}$ (including two perpetrators who were doctors, abusing their privileged access to prescription-only drugs) and is usually punished by imprisonment. In Brazil, two criminal cases of older men meeting teenage girls for sex involved pregnancies being ended by surreptitious vaginal application of misoprostol ${ }^{42}$.

\section{REPRODUCTIVE CONTROL PERPETRATED BY THE WIDER FAMILY}

In some settings, in-laws may perpetrate gender-based violence through a wide variety of types of abuse during pregnancy, at delivery and postpartum ${ }^{43}$. The degree to which such abuse during pregnancy overlaps with RC is not known.

\section{Control over family size}

In some cultural settings, the wider family and in particular older female relatives, may have societally endorsed control over reproductive decision-making. Patriarchal cultural norms, and contexts wherein brides live with the husband's family, may facilitate this kind of control. Examples from the literature include reports that assent from mothers-in-law is often necessary for decision-making on the composition of the family (one or two sons usually being thought to be needed) and also for sterilisation (a signal that the family is complete and the commonest form of fertility control used in India $)^{44}$. Contraceptive sabotage by proxy can occur. An example from the literature is a mother-in-law who puts pressure on her son not to use condoms ${ }^{44}$. Women with no sons may have low status and may suffer discrimination, which can act as an emotional means of controlling reproductive intention. 


\section{Coerced conception and pressure to conceive or continue a pregnancy}

In some situations the in-law family can exert a profound degree of control over their daughter-in-law's life if she is slow to conceive or does not conceive ${ }^{45}$. This may consist of forcing a woman to abandon use of contraception, or telling their son to leave her, have a baby with someone else or otherwise to punish her through emotional or physical abuse. Deprivations commonly inflicted on a daughter-in-law are restrictions to the supply of food, confining her to the house and other insults and humiliations. Family abusers use the same methods as partner abusers ${ }^{11}$; this behaviour is domestic violence but extends more widely than IPV.

In addition to coerced conception, coercion to continue with an established pregnancy against the wishes of the woman, may originate from the wider family ${ }^{6}$.

\section{Forced termination of a pregnancy}

Reproductive control in the form of forced abortion of a wanted pregnancy may be perpetrated against women, by the wider family. Coerced abortion may be part of a violent behaviour pattern, which includes IPV, rape and sometimes incest within familes ${ }^{36}$. In South Asia in particular, there are reports of abuse of women during pregnancy by in-laws, including forced abortion ${ }^{43}$. The abuse may be based upon intergenerational discordance between the family-building intentions of a woman and the expectations of the in-laws ${ }^{37}$.

\section{PERPETRATORS INVOLVED IN SEX TRAFFICKING AND SEXUAL EXPLOITATION}

Coerced abortion may also be part of organised criminal activity. This includes child sexual exploitation ${ }^{46}$. The pimp-prostitute relationship often exhibits coercive control and violence similar to IPV ${ }^{47}$. Coerced abortion has been described in victims of sex trafficking in the USA $^{48}$.

\section{DETECTION, EDUCATION, HARM REDUCTION AND PREVENTION}

Women subjected to RC may not necessarily have insight into their relationship, especially if there is no physical or sexual violence ${ }^{4}$. The degree of control that a male partner can have will vary from mild to extreme. Milder amounts of control may not be perceived by the victim as unhealthy or abusive. Women in a long-term relationship may become inured to significant levels of RC. 
Screening for RC should take place in maternity, sexual and reproductive health and abortion services and in general practice settings. Suggested screening questions have been formulated (see Figure 1$)^{49}$. Professionals have the opportunity not only to detect RC, but to discuss healthy relationships. Where necessary, help with negotiating condom use and, if reproductive control is disclosed, employing concealable methods may be offered. Healthcare professionals can also ensure that women know how to access emergency contraception. Injectables, implants, intrauterine contraception (if necessary with the threads cut short to avoid detection) and sterilisation, are possible concealable methods of contraception. This advice should take place within the wider context of helping women minimise or escape from situations of domestic violence, and of safeguarding activity.

There are examples of excellent educational materials on RC that have been developed 5051 . An educational intervention was found to reduce the odds of pregnancy coercion by $71 \%$ and to significantly increase the odds of ending a relationship due to perceptions that it was unhealthy ${ }^{52}$. The ARCHES study is under way; this will provide information about the efficacy of a brief intervention on the risk of $\mathrm{RC}^{53}$.

\section{DISCUSSION}

\section{Findings and interpretation}

Reproductive control is common; professionals working in women's health, sexual and reproductive health, abortion and maternity services should be aware of the concept and equipped to screen for it. RC is primarily carried out by intimate partners but is also perpetrated by the wider family and in organised criminal activity. The perpetrators' focus of control may vary, at times coercing pregnancy and at other times coercing abortion. Coerced abortion may be part of sex trafficking or sexual exploitation.

RC infringes women's reproductive rights and erodes women's reproductive autonomy. Past experience of RC adversely affects women's feelings of agency during sexual and contraceptive interactions.

\section{Relevance of the findings and implications for clinicians or policymakers}

Those working in health and social care specialties relating to women's health, and in general practice, should be aware of reproductive control. Reproductive control may be an underlying cause for contraceptive non-adherence. Healthcare professionals should be alert to it in consultations with women who are displaying behavioural patterns such as persistent lack of use of contraception (despite not wishing to become pregnant), frequent 
requests for emergency contraception, frequent attendances for pregnancy testing or STI testing and requests for more than one abortion.

There are now screening questions for its detection and interventions that can assist in reducing its risks. Women attending health services with escorts should, at some stage, be seen alone so that these sensitive issues can be raised and, if necessary, explored. Information may need to be shared with safeguarding agencies, especially with respect to younger women, or those who lack mental capacity.

Public health policy makers need to take account of RC as a causative factor in unintended pregnancy. The findings in this review reinforce the importance of teaching children about healthy relationships, including respect for partners and open communication about contraceptive use.

\section{Unanswered questions and future research}

Research so far has been almost exclusively undertaken in the USA; research in other countries is to be encouraged. There remains much to be learnt about RC and how it affects women. In particular, more research is needed on the non-physical elements of abusive relationships and how coercive control can be resisted. Also, more needs to be understood about whether $\mathrm{RC}$ relates to a particular partner or whether $\mathrm{RC}$ experiences with one partner negatively impact future sexual relationships.

More understanding of perpetrators' motivations for engaging in RC is needed. Further research should be conducted on the reasons partners engage in RC behaviours, as well as women's perceptions of partner intent. Young people are especially vulnerable to RC and research is needed which focuses on the dating relationships of young people.

As always, in an era of over-stretched resources and healthcare professionals, the most efficient and effective means of using routine healthcare consultations to identify and reduce the harms of reproductive control need to be identified and disseminated.

\section{Acknowledgement}

We thank Dr Victoria Newton for her helpful comments on an earlier draft of the manuscript. 
Table 1 Review search parameters

\begin{tabular}{|l|l|}
\hline Parameter & Definition \\
\hline Inclusion criteria & Heterosexual relationships \\
& RC of women by men \\
& RC as criminal activity \\
\hline Exclusion criteria & Same-sex relationships \\
& RC of men by women \\
& Negotiation of condom use \\
& Outcomes following RC e.g. STIs \\
& Intimate partner violence \\
& Coercion by HCPs to use LARC \\
& Coercion by HCPs to be sterilised \\
& Coercion by the state \\
\hline Language & Abstract in English \\
\hline Date range & 2010 to 2017 \\
\hline
\end{tabular}

Table 2 Prevalence of reproductive control in women

\begin{tabular}{|c|c|c|c|c|c|c|}
\hline Study & $\begin{array}{l}\text { Year of } \\
\text { publication }\end{array}$ & Country & Ages & Population/setting & Timespan & $\begin{array}{l}\text { Result } \\
(\%)\end{array}$ \\
\hline Black $^{54}$ & 2011 & USA & $\begin{array}{l}18 \text { and } \\
\text { over }\end{array}$ & Whole population & Ever & 9 \\
\hline Cannon $^{55}$ & 2017 & USA & 'Adult' & SRH & $\begin{array}{l}\text { Current } \\
\text { relationship }\end{array}$ & 25 \\
\hline Clark $^{23}$ & 2014 & USA & $18-44$ & Hospital O\&G & Ever & 16 \\
\hline Katz $^{10}$ & 2015 & USA & $17-25$ & Students & Ever & 30 \\
\hline Kazmerski $^{17}$ & 2015 & USA & $16-29$ & SRH & Previous 3 months & 14 \\
\hline Miller ${ }^{15}$ & 2010 & USA & $16-29$ & SRH & Ever & 19 \\
\hline Phillips ${ }^{56}$ & 2016 & USA & $18-45$ & Primary care & Ever & 24 \\
\hline Rosenfeld $^{57}$ & 2017 & USA & $18-44$ & Veterans & $\begin{array}{l}\text { Previous } 12 \\
\text { months }\end{array}$ & 11 \\
\hline Sutherland ${ }^{26}$ & 2015 & USA & $18-25$ & Students & Ever & 8 \\
\hline
\end{tabular}

$O \& G=$ obstetrics and gynaecology service attenders

$\mathrm{SRH}=$ sexual and reproductive health service attenders 
Figure 1 Screening questions for reproductive control

[Please place text in a box]

If not pregnant:

Does your partner support your decision about when or if you want to become pregnant?

If not trying to become pregnant:

Has your partner ever tried to get you pregnant when you did not want to be pregnant? Has your partner ever refused your request to use condoms?

If already pregnant:

Do you and your partner agree on what you should do about your pregnancy? 


\section{REFERENCES}

\section{References}

1. Shalev C. Rights to sexual and reproductive health: the ICPD and the Convention on the Elimination of all forms of Discrimination Against Women. Health \& Human Rights $J$ 2000;4:38-66.

2. Fawson PR, Wright RL, Jones $\mathrm{T}$, et al. Addressing barriers to reproductive autonomy among sexually active female university students in the United States. Women Health Open J 2017;SE(1):S3-S9.

3. Park J, Nordstrom SK, Weber KM, et al. Reproductive coercion: uncloaking an imbalance of social power. Am J Obstet Gynecol 2015 doi: http://dx.doi.org/10.1016/i.ajog.2015.08.045

4. Miller E, Silverman JG. Reproductive coercion and partner violence: implications for clinical assessment of unintended pregnancy. Expert Rev Obstet Gynecol 2010;5:51115.

5. Grace KT, Anderson JC. Reproductive coercion: a systematic review. Trauma, Violence, \& Abuse 2016;19:371-90.

6. Grace KT, Fleming C. A systematic review of reproductive coercion in international settings. World Medical and Health Policy 2016;8:382-408.

7. Miller E, Jordan B, Levenson R, et al. Reproductive coercion: connecting the dots between partner violence and unintended pregnancy. Contraception 2010;81:457-59.

8. Williamson E. Reproductive coercion. In: McOrmond-Plummer L, Levy-Peck JY, Easteal P, eds. Intimate partner sexual violence. London: Jessica Kingsley 2014.

9. Silverman JG, Raj A. Intimate partner violence and reproductive coercion: global barriers to women's reproductive control. PLoS Med 2014;11:e1001723.

10. Katz J, Poleshuck EL, Beach B, et al. Reproductive coercion by male sexual partners: associations with partner violence and College women's sexual health. $J$ Interpersonal Violence 2015;32:3301-20.

11. Williamson E. Living in the world of the domestic violence perpetrator: negotiating the unreality of coercive control. Violence Against Women 2010;16:1412-23.

12. Moore AM, Frohwirth L, Miller E. Male reproductive control of women who have experienced intimate partner violence in the United States. Soc Sci Med 2010;70:1737-44.

13. McCauley HL, Falb KL, Streich-Tilles T, et al. Mental health impacts of reproductive coercion among women in Côte d'Ivoire. Int J Gynecol Obstet 2014;127:55-59.

14. Hathaway JE, Mucci LA, Silverman JG, et al. Health status and health care use of Massachusetts women reporting partner abuse. Am J Prev Med 2010;19:302-07.

15. Miller E, Decker MR, McCauley HL, et al. Pregnancy coercion, intimate partner violence and unintended pregnancy. Contraception 2010;81:316-22.

16. Miller E, McCauley HL, Tancredi DJ, et al. Recent reproductive coercion and unintended pregnancy among female family planning clients. Contraception 2014;89:122-28.

17. Kazmerski T, McCauley HL, Jones $\mathrm{K}$, et al. Use of reproductive and sexual health services among family planning clinic clients exposed to partner violence and reproductive coercion. Matern Child Health J 2015;19:1490-96. 
18. Hall M, Chappell LC, Parnell BL, et al. Associations between intimate partner violence and termination of pregnancy: a systematic review and meta-analysis. PLoS Med 2014;11:e1001581.

19. Willie TC, Powell A, Callands T, et al. Investigating intimate partner violence victimization and reproductive coercion victimization among young pregnant and parenting couples: a longitudinal study. Psychology of Violence 2017 doi: http://dx.doi.org/10.1037/vio0000118

20. Falb KL, Annan J, Kpebo D, et al. Reproductive coercion and intimate partner violence among rural women in Côte d'Ivoire: a cross-sectional study. Afr J Reprod Health 2014;18:61-69.

21. Northridge JL, Silver EJ, Talib HJ, et al. Reproductive coercion in high school-aged girls: associations with reproductive health risk and intimate partner violence. J Pediatr Adolesc Gynecol 2017;30:603-08.

22. Thaller J, Messing JT. Reproductive coercion by an intimate partner: occurrence, associations, and interference with sexual health decision making. Health \& Social Work 2016;41:e11-e19.

23. Clark LE, Allen RH, Goyal V, et al. Reproductive coercion and co-occurring intimate partner violence in obstetrics and gynecology patients. AJOG 2014;210:e1-e8.

24. Holliday CN, McCauley HL, Silverman JG, et al. Racial/ethnic differences in women's experiences of reproductive coercion, intimate partner violence, and unintended pregnancy. J Women's Health 2017;26:828-35.

25. Thiel de Bocanegra $H$, Rostovtseva DP, Khera S, et al. Birth control sabotage and forced sex: experiences reported by women in domestic violence shelters. Violence Against Women 2010;16:601-12.

26. Sutherland MA, Fantasia $\mathrm{HC}$, Fontenot $\mathrm{H}$. Reproductive coercion and partner violence among college women. JOGNN 2015;44:218-27.

27. Nikolajski C, Miller E, McCauley HL, et al. Race and reproductive coercion: a qualitative assessment. Women's Health Issues 2015;25:216-23.

28. Teitelman AM, Tennille J, Bohinski JM, et al. Unwanted unprotected sex. Condom coercion by male partners and self-silencing of condom negotiation among adolescent girls. Advances in Nursing Science 2011;34:243-59.

29. Brodsky A. "Rape-adjacent': imagining legal responses to nonconsensual condom removal. Columbia J Gender \& Law 2017;32:183-210.

30. Trawick SM. Birth control sabotage as domestic violence: a legal response. California Law Review 2012;100:721-60.

31. Plunkett LA. Contraceptive sabotage. Columbia J Gender \& Law 2014;28:97-143.

32. CBC News. Condom piercer loses Supreme Court appeal Ottawa: CBC/Radio Canada; 2014 [cited 20147 March]. Available from: http://www.cbc.ca/news/canada/novascotia/condom-piercer-loses-supreme-court-appeal-1.2563227 accessed 7 March 2018.

33. Bell T. A new flushable pregnancy test could help women in abusive relationships. Vice 20188 March.

34. Kaity. It happened to me: I experienced reproductive coercion and gave myself an abortion New York: xoJane; 2015 [Available from: https://www.xojane.com/ithappened-to-me/ihtm-i-experienced-reproductive-coercion-and-gave-myself-anabortion accessed 14 March 2018. 
35. Chibber KS, Biggs MA, Robert SCM, et al. The role of intimate partners in women's reasons for seeking abortion. Women's Health Issues 2014;24:e131-e38.

36. McCloskey LA. The effects of gender-based violence on women's unwanted pregnancy and abortion. Yale J Biol \& Med 2016;89:153-59.

37. Pearson $\mathrm{E}$, Andersen $\mathrm{KL}$, Biswas $\mathrm{K}$, et al. Intimate partner violence and constraints to reproductive autonomy and reproductive health among women seeking abortion services in Bangladesh. Int J Gynecol Obstet 2017;136:290-97.

38. Silverman JG, Decker MR, McCauley HL, et al. Male perpetration of intimate partner violence and involvement in abortions and abortion-related conflict. AJPH 2010;100:1415-17.

39. Anonymous. Man gets six years for abortion pill smoothie. The Local 201517 March.

40. Rowlands S. Abortion pills: under whose control? J Fam Plann Reprod Health Care 2012;38:117-22.

41. Phillips K. A doctor laced his ex-girlfriend's tea with abortion pills and got three years in prison. Washington Post 201819 May.

42. Diniz D, Madeiro A. Cytotec and abortion: the police, the vendors and women [in Portuguese]. Ciênc saúde coletiva 2012;17:1795-804.

43. Raj A, Sabarwal S, Decker MR, et al. Abuse from in-laws during pregnancy and postpartum: qualitative and quantitative findings from low-income mothers of infants in Mumbai, India. Matern Child Health J 2011;15:700-12.

44. Char A, Saavala M, Kulmala T. Influence of mothers-in-law on young couples' family planning decisions in rural India. Reprod Health Matters 2010;18:154-62.

45. Gupta J, Falb K, Kpebo D, et al. Abuse from in-laws and associations with attempts to control reproductive decisons among rural women in Côte d'Ivoire: a cross-sectional study. BJOG 2012;119:1058-66.

46. Alderson KA. Child sexual exploitation. J Forensic Practice 2016;18:292-95.

47. Raphael J, Reichert JA, Powers M. Pimp control and violence: domestic sex trafficking of Chicago women and girls. Women \& Criminal Justice 2010;20:89-104.

48. Lederer $\amalg$, Wetzel $C A$. The health consequences of sex trafficking and their implications for identifying victims in healthcare facilities. Ann Health Law 2014;23:61-91.

49. ACOG. Reproductive and sexual coercion. Committee opinion no. 5. Obstet Gynec 2013;121:411-15.

50. Cappelletti M, Gatimu J, Shaw G. Exposing reproductive coercion: a toolkit for awareness raising, assessment, and intervention: FWHC, NCADV, NOMAS; 2014 [Available from: https://www.communitysolutionsva.org/files/RCtoolkit\%281\%29.pdf

51. Burton CW, Carlyle KE. Screening and intervening: evaluating a training program on intimate partner violence and reproductive coercion for family planning and home visiting providers. Fam Community Health 2015;38:227-39.

52. Miller E, Decker MR, McCauley HL. A family planning clinic partner violence intervention to reduce risk associated with reproductive coercion. Contraception 2011;83:274-80.

53. Tancredi DJ, Silverman JG, Decker MR, et al. Cluster randomized controlled trial protocol: addressing reproductive coercion in health settings (ARCHES). BMC Women's Health 2015;15:57.

54. Black MC, Basile KC, Breiding MJ, et al. The National Intimate Partner and Sexual Violence Survey (NISVS): 2010 summary report. Atlanta, GA: National Center for Injury Prevention and Control, Centers for Disease Control and Prevention, 2011. 
55. Cannon L, Bevilacqua K, Khan A, et al. Intimate partner violence, reproductive coercion, and contraception among patients in a reproductive health setting: a mixed methods study of patient preferences regarding a clinic-based intervention. Injury Prevention 2017;23 (Suppl 1):A26.

56. Phillips SJ, Bennett AH, Hacker MR, et al. Reproductive coercion: an under-recognized challenge for primary care patients. Fam Pract 2016;33:286-89.

57. Rosenfeld EA, Miller E, Zhao X, et al. Male partner reproductive coercion among women veterans. AJOG 2017;218:239.e1-39.e8. 